Article

\title{
PPAR $\alpha$ Agonist Suppresses Inflammation after Corneal Alkali Burn by Suppressing Proinflammatory Cytokines, MCP-1, and Nuclear Translocation of NF-KB
}

\author{
Yuichiro Nakano ${ }^{1,2}$, Masaaki Uchiyama ${ }^{1,2}$, Takeshi Arima ${ }^{1,2}$, Shinya Nagasaka ${ }^{2}$, \\ Tsutomu Igarashi ${ }^{1}\left(\mathbb{D}\right.$, Akira Shimizu ${ }^{2, *(1)}$ and Hiroshi Takahashi ${ }^{1}$ \\ 1 Department of Ophthalmology, Nippon Medical School, Tokyo 113-8603, Japan; \\ nakano1212@nms.ac.jp (Y.N.); uchiyama@nms.ac.jp (M.U.); takesuiii0714@nms.ac.jp (T.A.); \\ tutomu@nms.ac.jp (T.I.); tash@nms.ac.jp (H.T.) \\ 2 Department of Analytic Human Pathology, Nippon Medical School, Tokyo 113-8602, Japan; \\ 3mousquetaires51a@gmail.com \\ * Correspondence: ashimizu@nms.ac.jp; Tel.: +81-3-3822-2131; Fax: +81-3-5685-3067
}

Academic Editors: Raffaele Capasso and Fabio Arturo Iannotti

Received: 28 November 2018; Accepted: 24 December 2018; Published: 29 December 2018

\begin{abstract}
We investigated the effect of a peroxisome proliferator-activated receptor $\alpha$ (PPAR $\alpha$ ) agonist after corneal alkali injury. Fenofibrate $0.05 \%$ (PPAR $\alpha$ agonist group) or vehicle (Vehicle group) was topically instilled onto the rat cornea after injury. Histological, immunohistochemical, and real-time reverse transcription PCR analyses were performed. PPAR $\alpha$-positive cells were observed among basal cells of the corneal epithelium in normal and alkali-burned corneas. The number of infiltrating neutrophils and macrophages at the corneal limbus was lower in the PPAR $\alpha$ agonist group. Interleukin-1 $\beta$ (IL-1 $\beta$ ), IL-6, IL-8, monocyte chemoattractant protein-1 (MCP-1), and vascular endothelial growth factor-An mRNA expression was suppressed in the PPAR $\alpha$ agonist group compared to the Vehicle group. mRNA levels of nuclear factor kappa B (NF- $k B$ ) in corneal tissue were not different. However, NF-kB was expressed in the cytoplasm of basal cells in the PPAR $\alpha$ agonist group and in the nucleus in the Vehicle group. MCP-1 was more weakly expressed in the PPAR $\alpha$ agonist group. The PPAR $\alpha$ agonist inhibited inflammation during the early phase after injury. Anti-inflammatory effects of the PPAR $\alpha$ agonist included prevention of up-regulation of proinflammatory cytokines and MCP-1, and prevention of inflammatory cell infiltration into the injured cornea. Thus, a PPAR $\alpha$ agonist may be a promising treatment for corneal injury.
\end{abstract}

Keywords: fenofibrate; IKB- $\alpha$; IL-1 $\beta$; ophthalmic solution; VEGF-A

\section{Introduction}

For good vision, transparency of the cornea is essential. Injuries that damage the corneal stroma often result in scarring. Since inflammation and angiogenesis are deeply involved in scar tissue formation, agents that can suppress these phenomena have long been sought. One of the new suppression candidates is peroxisome proliferator-activated receptors (PPARs). PPAR is a nuclear receptor that belongs to the steroid hormone receptor superfamily. Three isoforms of PPARs, which vary in their tissue distribution, have been confirmed and include PPAR $\alpha, \beta$, and $\gamma$ [1-3]. PPAR $\alpha$ is localized in the liver, kidney, muscle, and heart; $\beta$ is ubiquitously expressed in many organs and tissues; and $\gamma$ is present in adipocytes and the small intestine [4,5]. Drugs that modulate PPARs are commonly used in clinical practice today. For example, selective PPAR $\alpha$ agonists such as fenofibrate 
are routinely used for the treatment of hyperlipidemia, whereas selective PPAR $\gamma$ agonists such as thiazolidinediones are used for the treatment of diabetes [6]. Selective PPAR $\beta$ agonists have also been examined regarding their usefulness in treating metabolic syndrome [7]. In addition to their role in the transcriptional regulation of metabolism, PPARs may be involved in controlling various inflammatory, angiogenic, and fibrotic physiological processes [8]. Thus, PPARs may represent novel targets for the treatment of inflammatory and vascular diseases [9].

Although the localization of PPARs in the cornea has not been well demonstrated, some studies have revealed that PPARs play a role in pathological conditions in this tissue. PPAR $\beta$ is upregulated during corneal epithelial wound healing, and pretreatment with a PPAR $\beta$ agonist inhibits inflammation-induced corneal epithelial cell death [10]. We also previously reported that an ophthalmic solution of a PPAR $\gamma$ agonist inhibits inflammation, decreases the fibrotic reaction, and prevents neovascularization in the cornea after alkali burn injury [11]. In addition, we reported that a PPAR $\alpha$ agonist suppresses neovascularization by reducing vascular endothelial growth factor (VEGF) and angiopoietin-2 in the cornea after alkali burn injury [12]. A recent study also demonstrated protective and anti-inflammatory effects of a PPAR $\alpha$ agonist in an experimental uveitis model [13].

$\operatorname{PPAR} \alpha$ agonists may regulate inflammation by maintaining a negative regulator, nuclear expression of the kappa light polypeptide gene enhancer in the B cell inhibitor, alpha (IKB- $\alpha)$. Nuclear factor kappa B (NF-kB) is a major transcription factor that plays a role in initiating proinflammatory immune responses. I $\kappa$ B- $\alpha$ mediates anti-inflammatory effects by inhibiting NF- $\kappa$ B activation. PPAR $\alpha$ agonists exert anti-inflammatory activities in different cell types by antagonizing

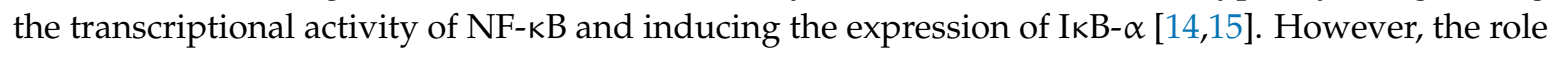
of PPAR $\alpha$ in corneal inflammation has yet to be definitively established.

In the present study, we investigated the localization of PPAR $\alpha$ in rat cornea and explored the effect of an ophthalmic solution of the selective PPAR $\alpha$ agonist, fenofibrate, following corneal alkali burn.

\section{Results}

\subsection{Localization of PPARs in the Rat Cornea}

In the normal rat cornea, PPAR $\alpha-, \beta-$, and $\gamma$-positive cells were observed among the epithelial basement cells (Figure 1A-C).

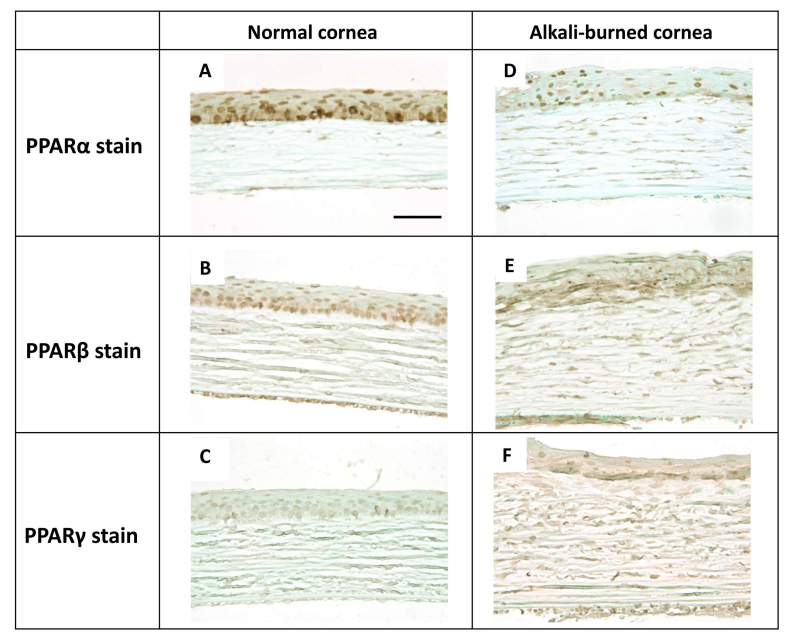

Figure 1. The expression of peroxisome proliferator-activated receptors (PPARs) in rat normal cornea and alkali-burned cornea at day 7. PPAR $\alpha-, \beta-$, and $\gamma$-positive cells were observed in the epithelial basement cells of normal cornea (center). (A-C; A: PPAR $\alpha$ stain, B: PPAR $\beta$ stain, C: PPAR $\gamma$ stain). In the alkali-burned cornea at day $7, \operatorname{PPAR} \alpha, \beta$, and $\gamma$ was expressed on the re-epithelialized basement cells (D-F; D: PPAR $\alpha$ stain, E: PPAR $\beta$ stain, F: PPAR $\gamma$ stain). Scale bar: $40 \mu \mathrm{m}$. 
A corneal burn was created in rats by treating the cornea with $\mathrm{NaOH}$. At day 7 in the cornea after alkali burn, PPAR $\alpha, \beta$, and $\gamma$ were expressed in the re-epithelialized basement cells (Figure 1D-F). In the epithelial basement cells in the center at $6 \mathrm{~h}$ and the limbus at day 1, more PPAR $\alpha$-positive cells (Figure 2A,B) were found than PPAR $\beta$ - (Figure 2C,D) and $\gamma$-positive cells (Figure 2E,F). Furthermore, $\operatorname{PPAR} \alpha, \beta$, and $\gamma$ were expressed on infiltrating neutrophils and macrophages at day 7 (Figure 3 ).

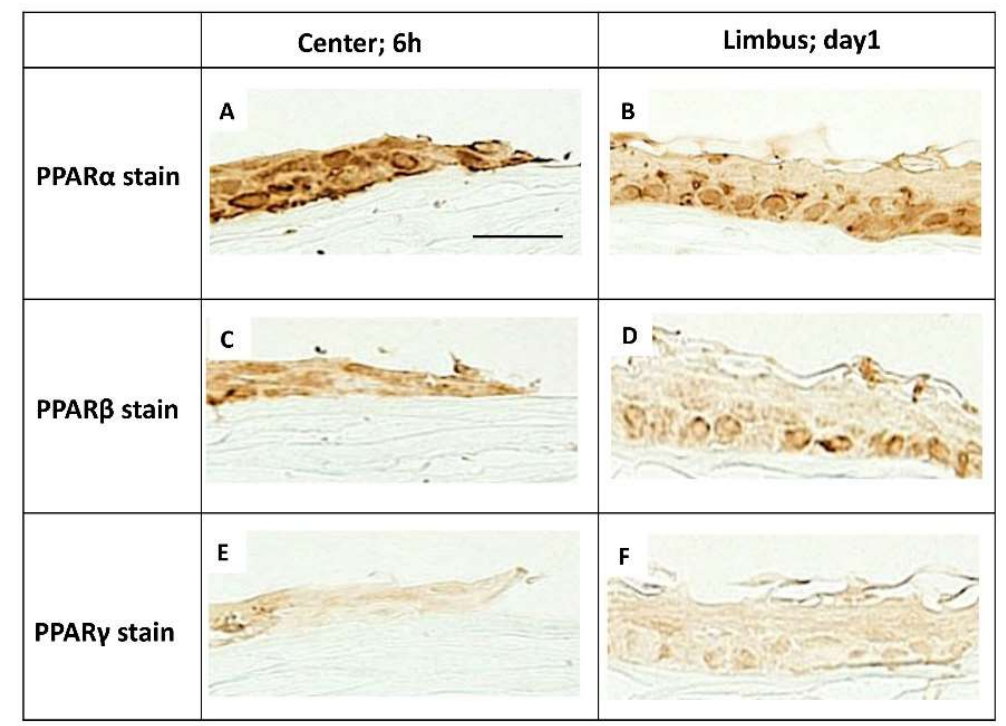

Figure 2. The expression of PPARs in epithelial cells in alkali-burned cornea. PPAR $\alpha, \beta$, and $\gamma$ was expressed on re-epithelialized basement cells. In the epithelial basement cells of center at $6 \mathrm{~h}$ and limbus at day 1 , the expression of $\operatorname{PPAR} \alpha(\mathbf{A}, \mathbf{B})$ seemed to be more prominent than the expression of $\operatorname{PPAR} \beta(\mathbf{C}, \mathbf{D})$ or PPAR $\gamma(\mathbf{E}, \mathbf{F})$. Scale bar: $20 \mu \mathrm{m}$.

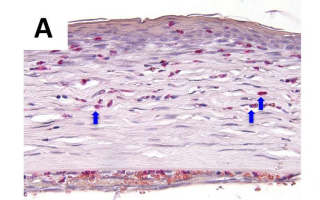

Esterase stain

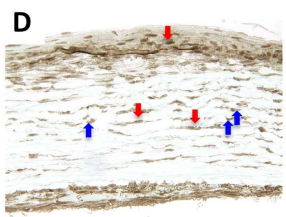

PPAR $\alpha$ stain

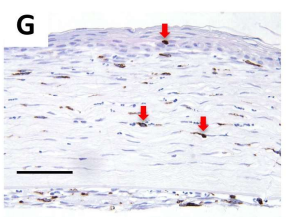

ED1 stain

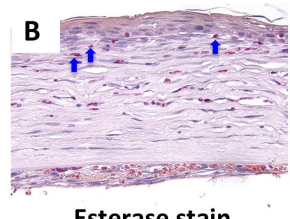

Esterase stain

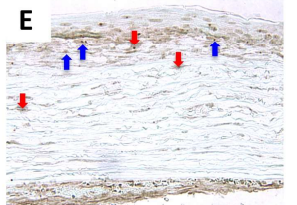

PPAR $\beta$ stain

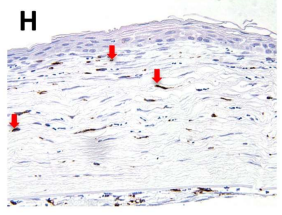

ED1 stain
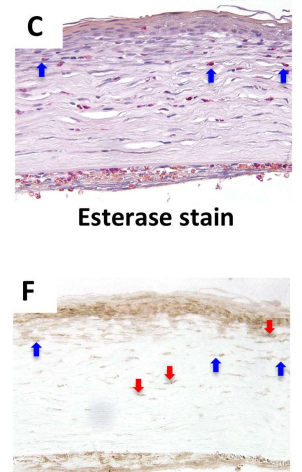

PPARy stain

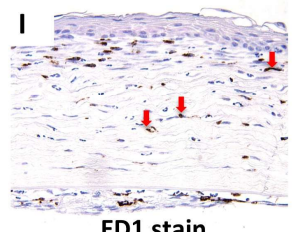

ED1 stain

Figure 3. The expression and distribution of PPARs in rat cornea and infiltration of neutrophils and macrophages in alkali-burned cornea at day 7. In the alkali-burned cornea at day 7, serial sections stained with naphthol AS-D chloroacetate esterase (A-C), PPAR $\alpha(\mathbf{D}), \operatorname{PPAR} \beta(\mathbf{E}), \operatorname{PPAR} \gamma(\mathbf{F})$, and ED1 (G-I) showed that PPARs was expressed on infiltrating naphthol AS-D chloroacetate esterase positive-neutrophils (blue arrows) and ED1-positive macrophages (red arrows). Scale bar: $50 \mu \mathrm{m}$. 


\subsection{Effects of an Ophthalmic Solution of a PPAR $\alpha$ Agonist after Alkali Burn Injury}

To test the effects of the PPAR $\alpha$ agonist, fenofibrate, on the cornea after alkali burn injury, an ophthalmic solution of fenofibrate (PPAR $\alpha$ agonist group) or vehicle (Vehicle group) was topically instilled onto the rat's ocular surfaces after the alkali injury. The number of infiltrating inflammatory cells, such as neutrophils and macrophages, was significantly lower in the PPAR $\alpha$ agonist group versus the Vehicle group at $6 \mathrm{~h}$ and on day 2 (Figures 4 and 5). The number of cells observed was: neutrophils; $6 \mathrm{~h}: 46.5 \pm 11.47$ cells $/ \times 400$ high-power field $(\mathrm{HPF})$ in the Vehicle group, $30.44 \pm 6.11$ cells/HPF in the PPAR $\alpha$ agonist group, $p<0.01$; day 1: $45.6 \pm 20.43$ cells/HPF in the Vehicle group, $37.21 \pm 20.21$ cells/HPF in the PPAR $\alpha$ agonist group; day 2: $53.07 \pm 16.56$ cells $/ \mathrm{HPF}$ in the Vehicle group, $23.8 \pm 12.8$ cells $/ \mathrm{HPF}$ in the PPAR $\alpha$ agonist group, $p<0.01$. Macrophages; $6 \mathrm{~h}$ : $39.0 \pm 14.47$ cells/HPF in the Vehicle group, $22.88 \pm 13.16$ cells/HPF in the PPAR $\alpha$ agonist group, $p<0.01$; day 1: $49.5 \pm 19.93$ cells/HPF in the Vehicle group, $34.36 \pm 16.35$ cells/HPF in the PPAR $\alpha$ agonist group; day 2: $54.43 \pm 16.7$ cells $/ \mathrm{HPF}$ in the Vehicle group, $31.5 \pm 9.05$ cells $/ \mathrm{HPF}$ in the PPAR $\alpha$ agonist group, $p<0.01$.
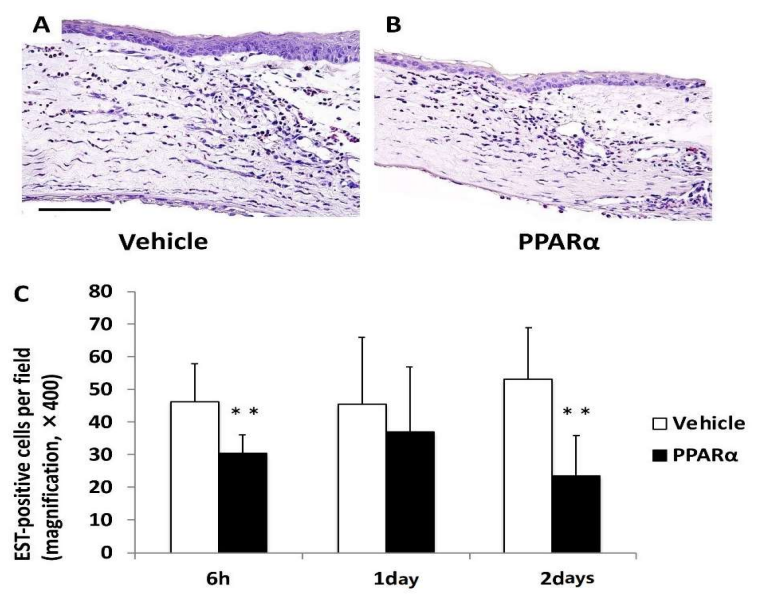

Figure 4. Infiltration of neutrophils in alkali-burned cornea. The number of infiltrating naphthol AS-D chloroacetate esterase (EST)-positive neutrophils (C) was significantly lower in the PPAR $\alpha$ agonist group (B) than the vehicle group (A) at $6 \mathrm{~h}$ and on day $2(* * p<0.01)$. Scale bar: $50 \mu \mathrm{m}$.

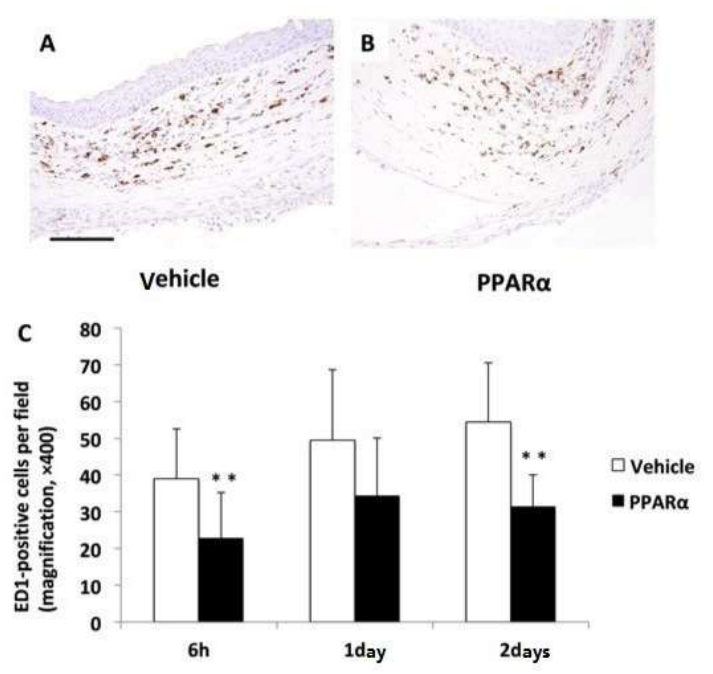

Figure 5. Infiltration of macrophages in alkali-burned cornea. The number of infiltrating ED1-positive macrophages (C) was significantly lower in the PPAR $\alpha$ agonist group (B) than the vehicle group (A) at $6 \mathrm{~h}$ and on day $\left.2{ }^{* *} p<0.01\right)$. Scale bar: $50 \mu \mathrm{m}$. 
Real-time RT-PCR was performed to assess the expression of genes encoding proinflammatory cytokines (interleukin [IL]-1 $\beta$ and IL-6), chemotactic chemokines (IL-8 and monocyte chemoattractant protein-1 (MCP-1)), and a factor involved in neovascularization (VEGF-A). In the alkali-burned corneas, the levels of mRNA for the proinflammatory chemokines and cytokines, IL-1 $\beta$, IL-6, IL-8, MCP-1, and VEGF-A, were increased at $6 \mathrm{~h}$ during development of corneal inflammation in the Vehicle and PPAR $\alpha$ agonist groups (Figure 6A-E). However, the increases in these molecules were suppressed by treatment with the ophthalmic solution of the PPAR $\alpha$ agonist after alkali exposure starting from $6 \mathrm{~h}$. The group treated with the ophthalmic solution of the $0.05 \%$ PPAR $\alpha$ agonist exhibited suppressed levels of IL-1 $\beta$, IL-6, and IL-8. We also observed an increase in the level of PPAR $\alpha$ in the PPAR $\alpha$ agonist group versus the Vehicle group (Figure $6 \mathrm{~F}$ ). For the alkali-burned corneas, we found no significant differences in the levels of NF- $\mathrm{KB}$ or IкB- $\alpha$ at $6 \mathrm{~h}$ during the development of corneal inflammation in the PPAR $\alpha$ agonist or Vehicle groups (Figure $6 \mathrm{G}, \mathrm{H}$ ).
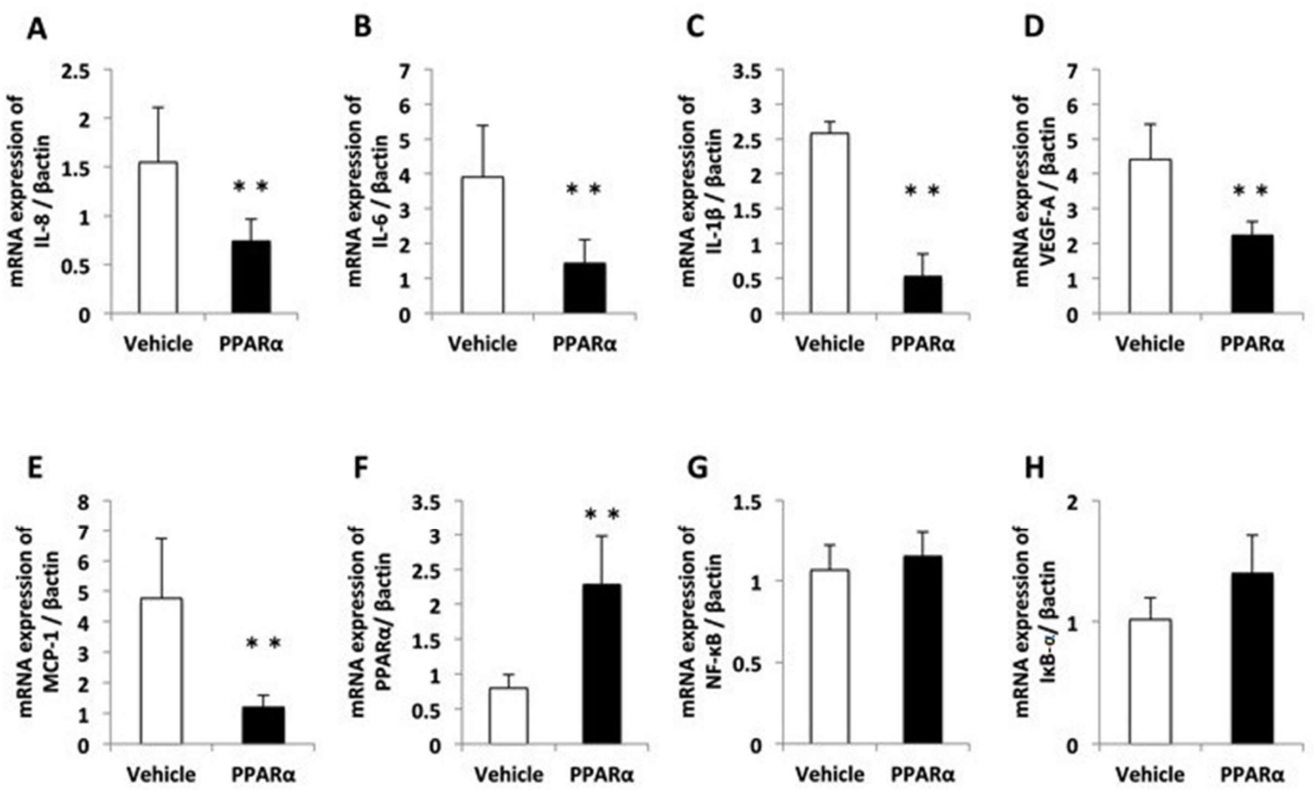

Figure 6. The expression of pro-inflammatory cytokines, chemokines, NF- $\kappa \mathrm{B}$, and IкB- $\alpha$ in the cornea after alkali burn injury. Quantification of the messenger ribonucleic acid expression levels of (A) IL-8 (CXCL8), (B) IL-6, (C) IL-1 $\beta$, (D) VEGF-A, (E) MCP-1, (F) PPAR $\alpha$, (G) NF-kB, and (H) I $k$ B- $\alpha$. The messenger ribonucleic acid (mRNA) expression levels were measured with real-time reverse transcription-polymerase chain reaction (RT-PCR), and were normalized to the level of $\beta$-actin. A significant difference was observed between the vehicle and PPAR $\alpha$ groups at $6 \mathrm{~h}(\mathrm{~A}-\mathrm{F})$ after injury. The levels of NF- $\kappa B$ and I $\kappa B-\alpha$ were no significant difference $(\mathbf{G}, \mathbf{H})$. The results are presented as the means \pm standard errors. ${ }^{* *} p<0.01$, compared with the vehicle group.

\subsection{NF- $\kappa B$, I $\kappa B-\alpha$, and $M C P-1$ Staining on Day 1}

In the normal rat cornea, NF-kB-positive areas showed weak, diffuse labeling of the cytoplasm of the epithelial basement cells in the center (Figure 7A) and limbus (Figure 7D). The epithelial basement cells displayed prominent nuclear NF- $\mathrm{kB}$ labeling throughout the epithelial basement cells during re-epithelialization, with weaker diffuse labeling of the cytoplasm observed in the alkali-burned cornea in the center (Figure 7B) and limbus (Figure 7E) in the Vehicle group. In the alkali-burned corneas, NF- $\mathrm{kB}$-positive areas were observed in the cytoplasm of the epithelial basement cells in the center (Figure 7C) and limbus (Figure 7F) in the PPAR $\alpha$ agonist group. 


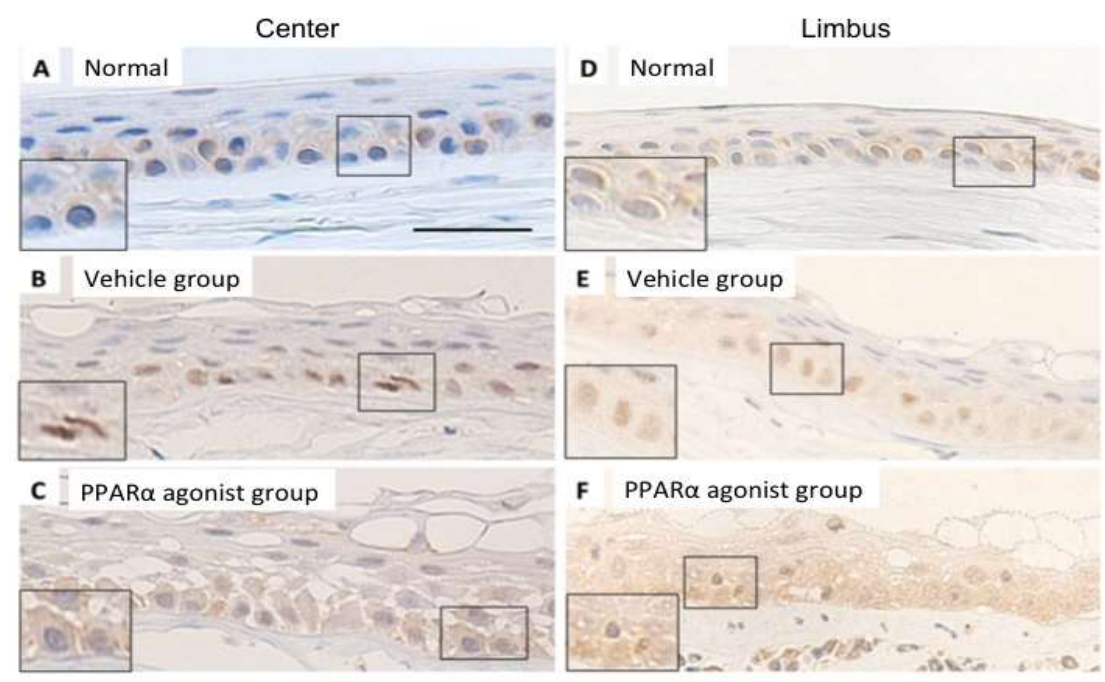

Figure 7. The localization of NF-kB p65 in normal cornea and in alkali-burned cornea in the vehicle and PPAR $\alpha$ agonist groups at day 1 . Immunohistochemical localization of NF- $\kappa \mathrm{B}$ in normal cornea of center (A) and limbus (D) showed the weaker diffuse labeling in the cytoplasm in the epithelial basement cells. In the alkali-burned cornea of center (B) and limbus (E) in the Vehicle group, NF-kB-positive nuclei were prominent in the epithelial basement cells, indicating nuclear translocation of NF- $\mathrm{kB}$ developed in the alkali-burned cornea. However, in the alkali-burned cornea of center $(\mathbf{C})$ and limbus $(\mathbf{F})$ in the PPAR $\alpha$ agonist groups, the location of NF- $\mathrm{kB}$ was noted in the cytoplasm of the epithelial basement cells, suggesting the prevention of nuclear translocation of NF- $\kappa$ B by PPAR $\alpha$ agonist. Scale bar: $20 \mu \mathrm{m}$.

In the normal cornea, no apparent labeling of IkB- $\alpha$ in the cytoplasm of the epithelial basement cells in the center (Figure 8A) and limbus (Figure 8D). In the alkali-burned cornea, IkB- $\alpha$-positive labeling was stronger in the PPAR $\alpha$ agonist group in the central cornea (Figure $8 \mathrm{C}$ ) and limbus (Figure $8 \mathrm{~F}$ ) compared to these regions of the Vehicle group (Figure 8B,E). Diffuse labeling of the cytoplasm of the epithelial basement cells was observed during re-epithelialization.

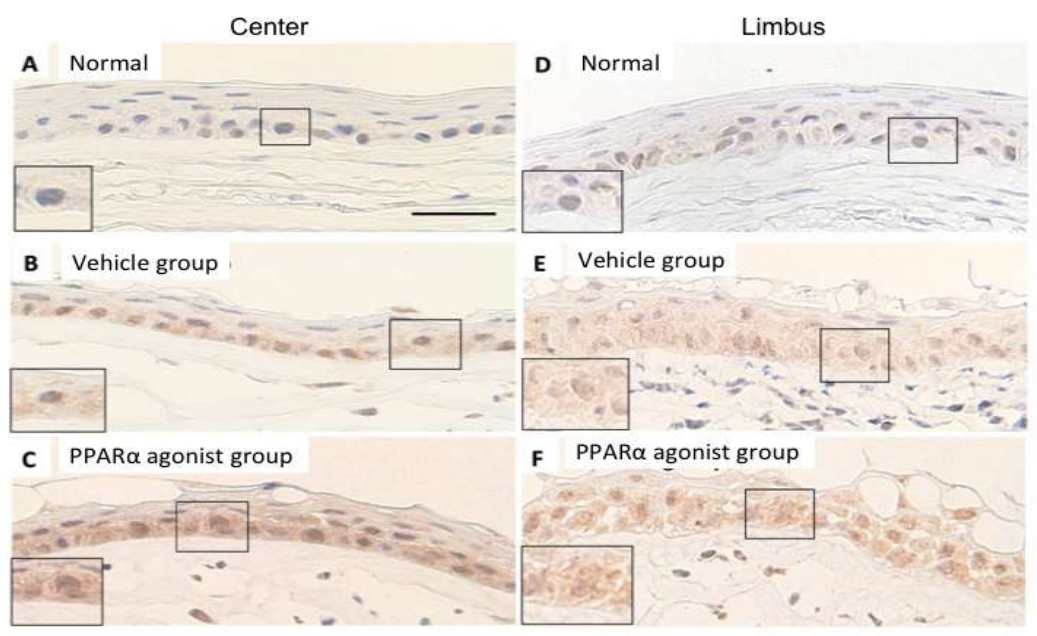

Figure 8. The localization of IкB- $\alpha$ in normal cornea and in alkali-burned cornea in the vehicle and PPAR $\alpha$ agonist groups at day 1. Immunohistochemical localization of I $\mathrm{K} B-\alpha$ in normal cornea of center (A) and limbus (D) showed the only a weak labeling in the cytoplasm in the epithelial basement cells. In the alkali-burned cornea of center $(\mathbf{B}, \mathbf{C})$ and limbus $(\mathbf{E}, \mathbf{F})$ in the Vehicle $(\mathbf{B}, \mathbf{E})$ and PPAR $\alpha$ agonist $(\mathbf{C}, \mathbf{F})$ groups, diffuse labeling of the cytoplasm of the epithelial basement cells was observed during re-epithelialization. However, the IKB- $\alpha$-positive labeling was stronger in the PPAR $\alpha$ agonist group $(\mathbf{C}, \mathbf{F})$ compared to these regions of the Vehicle group (B,E), suggesting that PPAR $\alpha$ agonist up-regulated IкB- $\alpha$ in the epithelial basement cells. Scale bar: $20 \mu \mathrm{m}$. 
The expression of MCP-1 were not observed in the center (Figure 9A) or limbus (Figure 9D) of the normal rat cornea. In the alkali-burned cornea, diffuse expression of the epithelial basement cells was observed during re-epithelialization in Vehicle group (Figure 9B,E). However, the expression of MCP-1 was weaker in the center (Figure 9C) and limbus (Figure 9F) of the PPAR $\alpha$ agonist group compared to these regions of the Vehicle group.

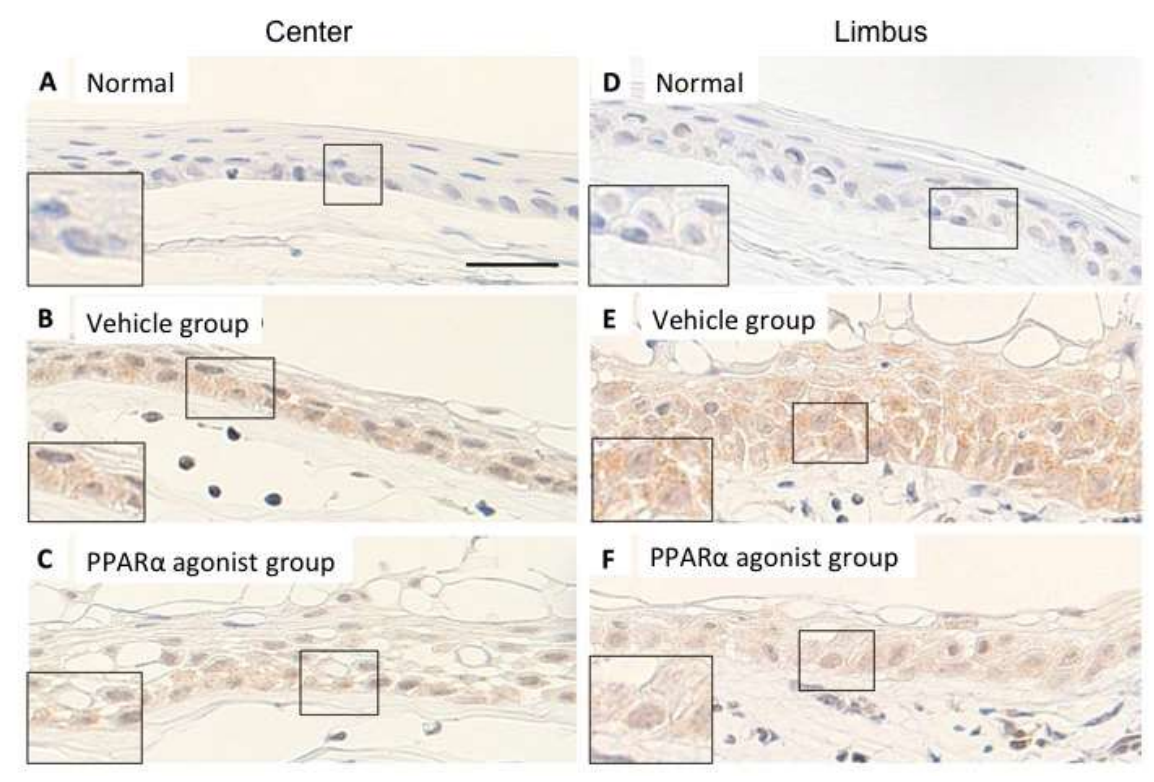

Figure 9. The expression of MCP-1 in rat normal cornea and in alkali-burned cornea in the vehicle and PPAR $\alpha$ agonist groups at day 1 . The expression of MCP-1 could not be detected in the epithelial basement cells in normal cornea of center (A) and of limbus (D). In the alkali-burned cornea of center $(\mathbf{B}, \mathbf{C})$ and limbus $(\mathbf{E}, \mathbf{F})$ in the Vehicle $(\mathbf{B}, \mathbf{E})$ and PPAR $\alpha$ agonist $(\mathbf{C}, \mathbf{F})$ groups, diffuse expression of MCP-1 in the epithelial basement cells was observed during re-epithelialization. However, the expression of MCP-1 was weaker in the PPAR $\alpha$ agonist group $(\mathbf{C}, \mathbf{F})$ compared to these regions of the Vehicle group (B,E), suggesting that PPAR $\alpha$ agonist inhibited the expression of MCP-1 in the epithelial basement cells. Scale bar: $20 \mu \mathrm{m}$.

\section{Discussion}

It has been reported that $\operatorname{PPAR} \alpha, \beta$, and $\gamma$ plays different roles in corneal wound healing. Administration of PPAR $\alpha$ not only reduces inflammation but also corneal neovascularization [12]. PPAR $\beta$ is involved in tissue repair and administration of PPAR $\beta$ agonist promotes the healing of corneal epithelial wounds [10]. The ophthalmic solution of the PPAR $\gamma$ agonist inhibits inflammation and furthermore promotes corneal wound healing by activating M2 macrophage [11]. Although localization of PPARs has been reported in various organs, localization in the cornea has yet to be shown. In our present study, we demonstrated the localization of PPARs in the rat cornea. PPAR $\alpha$-, $\beta$-, and $\gamma$-positive cells were observed among the basal cells of the epithelium in the normal cornea and in re-epithelialized basal cells after alkali burn. In addition, $\operatorname{PPAR} \alpha, \beta$, and $\gamma$ were expressed in the infiltrating neutrophils and macrophages. Among the observed subtypes, PPAR $\alpha$-positive cells were primarily found in the corneal regenerating epithelium, limbal epithelium, and infiltrating inflammatory cells. These results strongly suggest that PPAR $\alpha$ plays an important role in the wound healing process after a corneal burn.

Correspondingly, immunohistochemical and real-time RT-PCR analyses revealed that the PPAR $\alpha$ agonist, fenofibrate, inhibited proinflammatory reactions by decreasing the expression of IL-1 $\beta$, IL-6, IL-8, and MCP-1. These findings are in agreement with previous studies that showed that a PPAR $\alpha$ agonist plays a role in regulating the inflammatory response [14,16-18]. In addition, fenofibrate decreased the expression of VEGF-A, which may be associated with suppressing 
neovascularization during the early phase after an alkali injury [12]. In addition, in our current study, the PPAR $\alpha$ agonist, fenofibrate, decreased the expression of VEGF-A, which may be associated with suppressing neovascularization during the early phase after an alkali injury. The results were in good accordance with previous studies [12,19]. Furthermore, immunohistochemical and real-time RT-PCR analyses demonstrated that fenofibrate also increased the expression of $\operatorname{PPAR} \alpha$, which suggests self-inducing effects.

We then investigated the effect of the PPAR $\alpha$ agonist on the expression of NF-kB, which is a ubiquitous transcription factor that regulates key processes such as inflammation, apoptosis, stress response, wound healing, angiogenesis, and lymphangiogenesis [20-22]. Pro-inflammatory cytokines, IL-1 $\beta$, IL-6, IL-8, chemokine MCP-1, and VEGF are deeply involved in inflammation. In the process, activated NF- $\mathrm{kB}$ is known to be associated with production of pro-inflammatory cytokines, IL1 $\beta$, IL6,

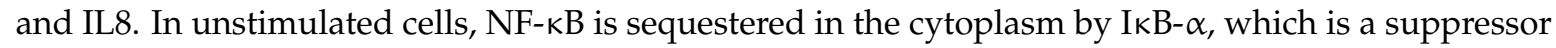
protein that binds to NF- $\kappa B$. NF- $k B$ activation is initiated by a signal that induces I $\kappa B$ degradation. NF- $\mathrm{KB}$ then enters the nucleus and activates specific genes [23-25]. In the present study, our real-time RT-PCR analysis did not identify significantly different levels of NF-KB or IKB- $\alpha$ between the PPAR $\alpha$ agonist and Vehicle groups. However, our immunohistochemical analysis demonstrated the effects of the PPAR $\alpha$ agonist on NF-KB expression. NF- $\mathrm{kB}$ was expressed in the cytoplasm of the basal cells in the PPAR $\alpha$ agonist group, whereas this protein was expressed in the nucleus in the Vehicle group. It has been known that NF- $\kappa B$ is located in the cytoplasm with the inhibitory protein $I \kappa B \alpha$. After the degradation of $I \kappa B, N F-\kappa B$ is activated and translocated into the nucleus where it binds to DNA [23-25]. Our results in the present study suggest that the PPAR $\alpha$ agonist inhibited the translocation of NF- $k B$ into the nucleus. During re-epithelialization, however, the I $\kappa \mathrm{B}-\alpha$-positive labeling of the cytoplasm of the basal cells in the PPAR $\alpha$ agonist group appeared stronger than that in the Vehicle group. This

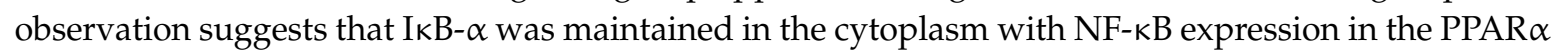
agonist group.

In the last step of our experiment, we investigated the effect of the PPAR $\alpha$ agonist on MCP-1. In the cornea, MCP-1 is expressed by epithelial cells and keratocytes [26]. Furthermore, MCP-1 is upregulated after an epithelial scrape injury [27]. In addition, introduction of MCP-1 into the rabbit cornea with a corneal micropocket assay leads to increased macrophage infiltration and angiogenesis [28]. Macrophages extravasate from the limbal vessels, infiltrate the stroma from superficial to deeper layers, and then migrate towards the corneal center in response to chemoattractants, such as MCP-1 [29,30]. In our present study, we showed that the MCP-1-positive areas appeared weaker in the PPAR $\alpha$ agonist group compared to the Vehicle group, which suggests that decreased infiltration of macrophages caused by the PPAR $\alpha$ agonist was associated with suppression of MCP-1 production.

In the present study, we clarified the expression of PPARs in normal and alkali-burned rat corneas. An ophthalmic solution of a PPAR $\alpha$ agonist inhibited inflammation starting from the early phase after alkali injury. The observed anti-inflammatory effects of the PPAR $\alpha$ agonist included the prevention of nuclear translocation of NF- $\mathrm{KB}$ and the decreased infiltration of inflammatory cells such as macrophages via suppression of MCP-1. These results suggest the possibility that an ophthalmic solution of a PPAR $\alpha$ agonist may be a promising treatment for corneal injury.

\section{Materials and Methods}

\subsection{Animal Model of Corneal Alkali Burn}

All procedures and animal experiments were performed in compliance with the guidelines set forth by the Experimental Animal Ethics Review Committee of Nippon Medical School, Tokyo, Japan (approval number 28-012) and the Association for Research in Vision and Ophthalmology (ARVO) Statement for the Use of Animals in Ophthalmic and Visual Research.

All experiments in the present study used 8-week-old male Wistar rats (Sankyo Laboratory Service, Tokyo, Japan). After placing the animals under general isoflurane anesthesia, a corneal alkali 
burn was created by placing a $3.2 \mathrm{~mm}$ diameter circular piece of filter paper soaked in $1 \mathrm{~N} \mathrm{NaOH}$ on the central cornea for $1 \mathrm{~min}$. The cornea was immediately rinsed with $40 \mathrm{~mL}$ physiologic saline after the alkali exposure. This procedure was performed unilaterally in each rat.

\subsection{Ophthalmic Solution of PPAR $\alpha$ Agonist}

Two kinds of ophthalmic solutions, a vehicle solution and a $0.05 \%$ fenofibrate hydrochloride solution, were compounded and used to compare the effect of the PPAR $\alpha$ agonist. Ophthalmic vehicle solution was prepared using $0.1 \mathrm{~mL}$ polyoxyethylene sorbitan monooleate (Wako Pure Chemical Industries, Osaka, Japan) and 100 mL NaCl-based PBS (0.01 M; pH 7.4), which was prepared with disodium hydrogen phosphate dodecahydrate $(232 \mathrm{~g})$, sodium dihydrogen phosphate dihydrate $(23.7 \mathrm{~g})$, and distilled water $(4000 \mathrm{~mL})$. To prepare the $0.05 \%$ fenofibrate hydrochloride ophthalmic solution, we added $10 \mathrm{mg}$ fenofibrate (Wako Pure Chemical Industries) to $20 \mathrm{~mL}$ vehicle solution. Fenofibrate is poorly soluble in aqueous solutions, therefore, fenofibrate hydrochloride ophthalmic solution was stirred for $70 \mathrm{~min}$. All ophthalmic solutions were recognized $\mathrm{pH} 3.7$ to $\mathrm{pH} 3.75$ and stored at $4{ }^{\circ} \mathrm{C}$ in a refrigerator, and used within a month of the initial compounding without sterile filtration.

\subsection{Treatment with the Ophthalmic Solutions}

Ophthalmic solutions were not used for comparisons of PPAR localization. To study the role of PPAR $\alpha, 0.05 \%$ fenofibrate hydrochloride ophthalmic solution (the PPAR $\alpha$ agonist group) or vehicle (the Vehicle group) was topically instilled onto the rat's ocular surfaces immediately after the alkali injury ( $n=10$ per time point). Topical administration was performed twice a day until the endpoint. The study did not use any of the contralateral eyes. At the endpoint ( $6 \mathrm{~h}$, day 1 , day 2 , or day 7), after macroscopic examination, all rats were euthanized by exsanguination under general isoflurane anesthesia.

\subsection{Histological and Immunohistochemical Analyses}

For light microscopy (Biological Microscope, BX51 Olympus Co., Tokyo, Japan) analysis, after fixing the eyeballs in $10 \%$ buffered formalin, samples were embedded in paraffin. To compare the expression and localization of the PPAR subtypes, immunostaining was performed in both the normal cornea and the alkali-burned cornea (at $6 \mathrm{~h}$, day 1, or day 7) without the use of ophthalmic solution. Histological and immunohistochemical analyses were then performed with the alkali-burned eyes (at $6 \mathrm{~h}$, day 1, and day 2) to compare the effects of the PPAR $\alpha$ agonist. Naphthol AS-D chloroacetate esterase staining was performed to detect infiltrating neutrophils. All primary antibodies used for the immunohistochemical analysis were selected based on their ability to cross-react with rat tissues. The antibodies used in the present study included: (1) monoclonal mouse anti-rat ED1 antibody (BMA, Nagoya, Japan), which was used to detect infiltrating macrophages; (2) polyclonal rabbit anti-rat PPAR $\alpha$ antibody (Thermo Scientific, Pierce Biotechnology, Rockford, IL, USA), which was used to detect PPAR $\alpha$-expressing cells; (3) polyclonal rabbit anti-rat PPAR $\beta$ antibody (Thermo Scientific), which was used to detect PPAR $\beta$-expressing cells; (4) monoclonal mouse anti-rat PPAR $\gamma$ antibody (Santa Cruz Biotechnology, Santa Cruz, CA, USA), which was used to detect PPAR $\gamma$-expressing cells; (5) polyclonal rabbit anti-rat NF-kB p65 antibody (Thermo Scientific); (6) monoclonal mouse anti-rat I $\mathrm{B}-\alpha$ antibody (Santa Cruz Biotechnology, Dallas, TX, USA); and (7) monoclonal mouse anti-rat MCP-1 (MB10) antibody (IBL, Gunma, Japan), which were used to detect the major transcription factors involved in initiating proinflammatory immune responses. Immunohistochemistry for ED1,

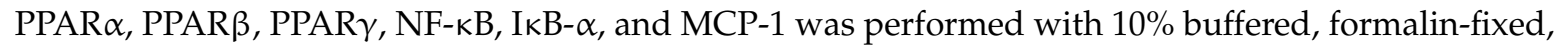
paraffin-embedded tissue sections. As a control, the immunohistochemistry experiments were performed without the primary antibody or with irrelevant primary antibodies. Specimen staining was performed using the standard avidin-biotin-peroxidase complex technique. 


\subsection{Real-Time RT-PCR}

For real-time RT-PCR, corneal tissues were removed from the enucleated eyes, immediately placed into RNAlater solution (Life Technologies, Carlsbad, CA, USA), and stored at $-80{ }^{\circ} \mathrm{C}$ until analysis. To compare the effects of the PPAR $\alpha$ agonist, we used real-time RT-PCR to examine the mRNA expression levels of IL-1 $\beta$, IL-6, IL-8 (CXCL8), MCP-1/CCL2, VEGF-A, PPAR $\alpha$, NF-kB, and IKB- $\alpha$. The Qiagen RNeasy Mini Kit (Qiagen, Hilden, Germany) was used to extract total RNA from corneas, and the NanoDrop ND-1000 V 3.2.1 Spectrophotometer (NanoDrop Technologies, Wilmington, DE, USA) was used to measure the RNA concentration and purity (A260/A280), in accordance with the manufacturers' protocols. The purified total RNA had an A260/A280 ratio of 1.9-2.2. The High Capacity cDNA Reverse Transcription Kit (Applied Biosystems, Foster, CA, USA) was used to create cDNA libraries from $4 \mu \mathrm{g}$ total RNA, in accordance with the manufacturer's protocol. To determine the gene expression levels, we analyzed $0.3 \mu \mathrm{L}$ cDNA with real-time quantitative RT-PCR using the THUNDERBIRD SYBR qPCR Mix (Toyobo, Osaka, Japan) based on real-time detection of accumulated fluorescence, in accordance with the manufacturer's instructions (ABI PRISM 7900HT, Applied Biosystems). To calculate the normalized value of the mRNA expression in each sample, the relative quantity of the relevant primers was divided by the quantity of the housekeeping gene, $\beta$-actin. Sequences of the real-time RT-PCR primers used in the analyses are listed in Table 1. The SDS 2.3 software program (Applied Biosystems, Foster, CA, USA) was used for all quantifications.

Table 1. Primers used for real-time RT-PCR.

\begin{tabular}{ccc}
\hline Gene & Forward Primer Sequence $\mathbf{( 5}^{\prime} \mathbf{-} \mathbf{3}^{\prime} \mathbf{)}$ & Reverse Primer Sequence $\mathbf{( 5}^{\prime} \mathbf{- 3}^{\prime} \mathbf{)}$ \\
\hline$I L-8(C X C L 8)$ & CCCCCATGGTTCAGAAGATTG & TTGTCAGAAGCCAGCGTTCAC \\
$I L-6$ & GTCAACTCCATCTGCCCTTCAG & GGCAGTGGCTGTCAACAACAT \\
$I L-1 \beta$ & TACCTATGTCTTGCCCGTGGAG & ATCATCCCACGAGTCACAGAGG \\
$V E G F-A$ & TGTGCGGGCTGCTGCAATGAT & TGTGCTGGCTTTGGTGAGGTTTGA \\
$M C P-1(C C L 2)$ & AGCCAGATGCAGTTAATGCCC & ACACCTGCTGCTGGTGATTCTC \\
$P P A R \alpha$ & TGAACAAAGACGGGATG & TCAAACTTGGGTTCCATGAT \\
$N F-\kappa B$ & GGCAGCACTCCTTATCAA & GGTGTCGTCCCATCGTAG \\
$I \kappa B-\alpha$ & TGACCATGGAAGTGATTGGTCAG & GATCACAGCCAAGTGGAGTGGA \\
$\beta-a c t i n$ & ACCACCATGTACCCAGGCATT & CCACACAGAGTACTTGCGCTCA \\
\hline
\end{tabular}

\subsection{Statistical Analyses}

All results are expressed as means \pm standard error. The unpaired Student's $t$-test was performed with an analytical software program (Excel, Microsoft, Redmond, WA, USA) to evaluate the differences.

\section{Conclusions}

In the present study, we demonstrated that PPAR $\alpha$ agonist ophthalmic solution suppresses inflammation after corneal alkali burn by suppressing proinflammatory cytokines and MCP-1, and the prevention of nuclear translocation of NF-KB in injured cornea. PPAR $\alpha$ agonist ophthalmic solution may be a promising treatment for corneal injury.

\section{Reference}

Author Contributions: Conceptualization, H.T. and A.S.; Methodology, M.U.; Software, Y.N.; Validation, A.S., and M.U.; Formal Analysis, Y.N., S.N., and T.A.; Investigation, Y.N., S.N., and T.A.; Resources, M.U.; Data Curation, H.T.; Writing-Original Draft Preparation, Y.N.; Writing-Review \& Editing, T.I..; Visualization, T.I..; Supervision, H.T.; Project Administration, A.S.; Funding Acquisition, A.S.

Funding: This research was supported by Nippon Medical School Grant-in-Aid for Medical Research.

Acknowledgments: The authors would like to express special thanks to Takashi Arai, Mitsue Kataoka, Kyoko Wakamatsu, Arimi Ishikawa, and Naomi Kuwahara for their expert technical assistance. 
Conflicts of Interest: The authors declare no conflicts of interest. The funding organization had no role in the design or conduct of this research.

\section{References}

1. Gottlicher, M.; Widmark, E.; Li, Q.; Gustafsson, J.A. Fatty acids activate a chimera of the clofibric acid-activated receptor and the glucocorticoid receptor. Proc. Natl. Acad. Sci. USA 1992, 89, 4653-4657. [CrossRef] [PubMed]

2. Issemann, I.; Green, S. Activation of a member of the steroid hormone receptor superfamily by peroxisome proliferators. Nature 1990, 347, 645-650. [CrossRef] [PubMed]

3. Tontonoz, P.; Hu, E.; Graves, R.A.; Budavari, A.I.; Spiegelman, B.M. mPPAR gamma 2: Tissue-specific regulator of an adipocyte enhancer. Genes Dev. 1994, 8, 1224-1234. [CrossRef] [PubMed]

4. Lee, C.H.; Olson, P.; Evans, R.M. Minireview: Lipid metabolism, metabolic diseases, and peroxisome proliferator-activated receptors. Endocrinology 2003, 144, 2201-2207. [CrossRef] [PubMed]

5. Li, S.; Nagothu, K.K.; Desai, V.; Lee, T.; Branham, W.; Moland, C.; Megyesi, J.K.; Crew, M.D.; Portilla, D. Transgenic expression of proximal tubule peroxisome proliferator-activated receptor-alpha in mice confers protection during acute kidney injury. Kidney Int. 2009, 76, 1049-1062. [CrossRef] [PubMed]

6. Desvergne, B.; Wahli, W. Peroxisome proliferator-activated receptors: Nuclear control of metabolism. Endocr. Rev. 1999, 20, 649-688. [CrossRef] [PubMed]

7. Mackenzie, L.S.; Lione, L. Harnessing the benefits of PPAR $\beta / \delta$ agonists. Life Sci. 2013, 93, 963-967. [CrossRef]

8. Zhang, S.; Gu, H.; Hu, N. Role of Peroxisome Proliferator-Activated Receptor $\gamma$ in Ocular Diseases. J. Ophthalmol. 2015, 2015, 275435. [CrossRef]

9. Balachandar, S.; Katyal, A. Peroxisome proliferator activating receptor (PPAR) in cerebral malaria (CM): A novel target for an additional therapy. Eur. J. Clin. Microbiol. 2011, 30, 483-498. [CrossRef]

10. Nakamura, Y.; Nakamura, T.; Tarui, T.; Inoue, J.; Kinoshita, S. Functional role of PPARdelta in corneal epithelial wound healing. Am. J. Pathol. 2012, 180, 583-598. [CrossRef]

11. Uchiyama, M.; Shimizu, A.; Masuda, Y.; Nagasaka, S.; Fukuda, Y.; Takahashi, H. An ophthalmic solution of a peroxisome proliferator-activated receptor gamma agonist prevents corneal inflammation in a rat alkali burn model. Mol. Vis. 2013, 19, 2135-2150. [PubMed]

12. Arima, T.; Uchiyama, M.; Nakano, Y.; Nagasaka, S.; Kang, D.; Shimizu, A.; Takahashi, H. Peroxisome proliferator-activated receptor alpha agonist suppresses neovascularization by reducing both vascular endothelial growth factor and angiopoietin-2 in corneal alkali burn. Sci. Rep. 2017, 7, 17763. [CrossRef] [PubMed]

13. Shen, W.; Gao, Y.; Lu, B.; Zhang, Q.; Hu, Y.; Chen, Y. Negatively regulating TLR4/NF- $k B$ signaling via PPAR $\alpha$ in endotoxin-induced uveitis. BBA-Mol. Basis Dis. 2014, 1842, 1109-1120. [CrossRef] [PubMed]

14. Delerive, P.; Gervois, P.; Fruchart, J.C.; Staels, B. Induction of IkB $\alpha$ expression as a mechanism contributing to the anti-inflammatory activities of PPAR $\alpha$ activators. J. Biol. Chem. 2000, 275, 36703-36707. [CrossRef] [PubMed]

15. Jones, D.C.; Ding, X.; Daynes, R.A. Nuclear receptor peroxisome proliferator-activated receptor $\alpha(\operatorname{PPAR} \alpha)$ is expressed in resting murine lymphocytes. The PPAR $\alpha$ in T and B lymphocytes is both transactivation and transrepression competent. J. Biol. Chem. 2002, 277, 6838-6845. [CrossRef] [PubMed]

16. Cunard, R.; DiCampli, D.; Archer, D.C.; Stevenson, J.L.; Ricote, M.; Glass, C.K.; Kelly, C.J. WY14,643, a PPAR $\alpha$ ligand, has profound effects on immune responses in vivo. J. Immunol. 2002, 169, 6806-6812. [CrossRef] [PubMed]

17. Delerive, P.; De Bosscher, K.; Besnard, S.; Vanden Berghe, W.; Peters, J.M.; Gonzalez, F.J.; Fruchart, J.C.; Tedgui, A.; Haegeman, G.; Staels, B. Peroxisome proliferator-activated receptor $\alpha$ negatively regulates the vascular inflammatory gene response by negative cross-talk with transcription factors NF-kB and AP-1. J. Biol. Chem. 1999, 274, 32048-32054. [CrossRef] [PubMed]

18. Chinetti, G.; Lestavel, S.; Bocher, V.; Remaley, A.T.; Neve, B.; Torra, I.P.; Teissier, E.; Minnich, A.; Jaye, M.; Duverger, N.; et al. PPAR- $\alpha$ and PPAR- $\gamma$ activators induce cholesterol removal from human macrophage foam cells through stimulation of the ABCA1 pathway. Nat. Med. 2001, 7, 53-58. [CrossRef] 
19. Panigrahy, D.; Kaipainen, A.; Huang, S.; Butterfield, C.E.; Barnés, C.M.; Fannon, M.; Laforme, A.M.; Chaponis, D.M.; Folkman, J.; Kieran, M.W. PPAR $\alpha$ agonist fenofibrate suppresses tumor growth through direct and indirect angiogenesis inhibition. Proc. Natl. Acad. Sci. USA 2008, 105, 985-990. [CrossRef]

20. Srivastava, S.K.; Ramana, K.V. Focus on molecules: Nuclear factor-кB. Exp. Eye Res. 2009, 88, 2-3. [CrossRef]

21. Lan, W.; Petznick, A.; Heryati, S.; Rifada, M.; Tong, L. Nuclear Factor-kappaB: Central regulator in ocular surface inflammation and diseases. Ocul. Surf. 2012, 10, 137-148. [CrossRef] [PubMed]

22. Wang, C.; Zeng, L.; Zhang, T.; Liu, J.; Wang, W. Tenuigenin Prevents IL-1 $\beta$-induced Inflammation in Human Osteoarthritis Chondrocytes by Suppressing PI3K/AKT/NF-kB Signaling Pathway. Inflammation 2016, 39, 807-812. [CrossRef] [PubMed]

23. Li, Q.; Verma, I.M. NF-кB regulation in the immune system. Nat. Rev. Immunol. 2002, 2, 725-734. [CrossRef] [PubMed]

24. Silverman, N.; Maniatis, T. NF-кB signaling pathways in mammalian and insect innate immunity. Gene. Dev. 2001, 15, 2321-2342. [CrossRef] [PubMed]

25. Sato, K.; Mihara, Y.; Kanai, K.; Yamashita, Y.; Kimura, Y.; Itoh, N. Tyrosol ameliorates lipopolysaccharide-induced ocular inflammation in rats via inhibition of nuclear factor (NF)- $\mathrm{kB}$ activation. J. Vet. Med. Sci. 2016, 78, 1429-1438. [CrossRef] [PubMed]

26. Ebihara, N.; Yamagami, S.; Yokoo, S.; Amano, S.; Murakami, A. Involvement of C-C chemokine ligand 2-CCR2 interaction in monocyte-lineage cell recruitment of normal human corneal stroma. J. Immunol. 2007, 178, 3288-3292. [CrossRef] [PubMed]

27. Hong, J.W.; Liu, J.J.; Lee, J.S.; Mohan, R.R.; Mohan, R.R.; Woods, D.J.; He, Y.G.; Wilson, S.E. Proinflammatory chemokine induction in keratocytes and inflammatory cell infiltration into the cornea. Investig. Ophth. Vis. Sci. 2001, 42, 2795-2803.

28. Goede, V.; Brogelli, L.; Ziche, M.; Augustin, H.G. Induction of inflammatory angiogenesis by monocyte chemoattractant protein-1. Int. J. Cancer 1999, 82, 765-770. [CrossRef]

29. O'Brien, T.P.; Li, Q.; Ashraf, M.F.; Matteson, D.M.; Stark, W.J.; Chan, C.C. Inflammatory response in the early stages of wound healing after excimer laser keratectomy. Arch. Ophthalmol.-Chic. 1998, 116, 1470-1474. [CrossRef]

30. Liu, Q.; Smith, C.W.; Zhang, W.; Burns, A.R.; Li, Z. NK cells modulate the inflammatory response to corneal epithelial abrasion and thereby support wound healing. Am. J. Pathol. 2012, 181, 452-462. [CrossRef]

Sample Availability: There was no sample of the compounds by the authors in this experiment.

(C) 2018 by the authors. Licensee MDPI, Basel, Switzerland. This article is an open access article distributed under the terms and conditions of the Creative Commons Attribution (CC BY) license (http:// creativecommons.org/licenses/by/4.0/). 